
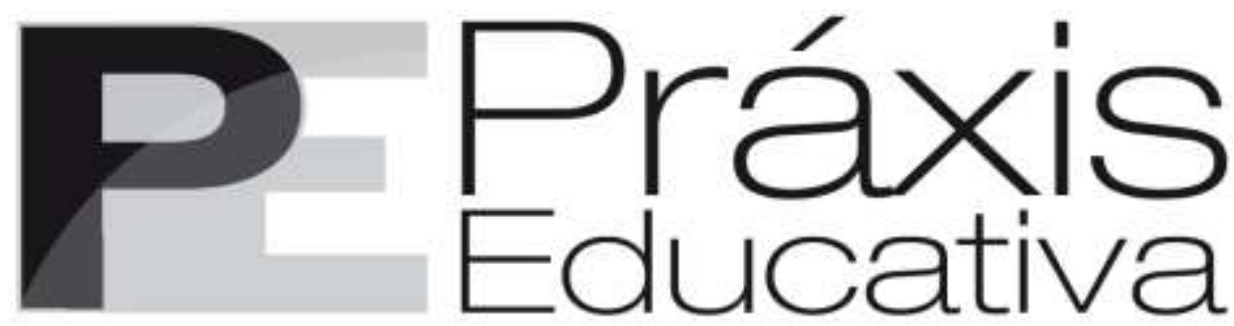

ISSN 1809-4031

elSSN 1809-4309

https://doi.org/10.5212/PraxEduc.v.17.19492.010

Dossiê: Relações étnico-raciais: práticas e reflexões pedagógicas em contextos, espaços e tempos

\title{
A significação do negro em materiais didáticos: uma análise semântica de atividades relacionadas ao Dia Nacional da Consciência Negra
}

The meaning of the black person in teaching materials: a semantic analysis of activities related to the National Day of Black Consciousness El significado del negro en materiales didácticos: un análisis semántico de
las actividades relacionadas con el Día Nacional de la Conciencia Negra

\author{
Florisbete de Jesus Silva* \\ https://orcid.org/0000-0002-1074-4543 \\ Leonardo Lacerda Campos ${ }^{* *}$ \\ iD https://orcid.org/0000-0002-5541-2307
}

\begin{abstract}
Resumo: O objetivo deste artigo foi analisar como o negro é significado em atividades didáticas desenvolvidas para alunos/as do Ensino Fundamental, expostas na rede social Pinterest, para serem aplicadas em salas de aula no Dia Nacional da Consciência Negra. As discussões foram fundamentadas por teorias sociais que versam sobre a Lei № 10.639, de 9 de janeiro de 2003, e sobre as questões raciais. O aporte teórico de análise foi a Semântica Enunciativa do Acontecimento, teoria semântica desenvolvida pelo Professor Eduardo Guimarães, a qual considera o estudo da enunciação como o lugar onde o sentido é historicamente construído na relação do sujeito com a língua, no acontecimento, e o texto é visto como uma unidade complexa de significação que integra enunciados, os quais apresentam no seu funcionamento uma consistência interna e uma dependência relativa, que os fazem significar. Os resultados da análise
\end{abstract}

\footnotetext{
${ }^{*}$ Doutoranda em Linguística, na Universidade Estadual de Campinas (Unicamp). Mestra em Linguística pela Universidade Estadual do Sudoeste da Bahia (Uesb), Vitória da Conquista. Mestra em Educação pela Universidade Lusófona de Humanidades e Tecnologia (ULHT), Lisboa, Portugal. Professora da Faculdade Nossa Senhora de Lourdes (FNSL), Porto Seguro, Bahia. Professora de Língua Portuguesa na Rede Municipal de Porto Seguro. Pesquisadora do Grupo de Pesquisa Linguagem, Enunciação, Discurso (LED) da Unicamp e do Grupo de Pesquisa em Estudos Semânticos (Gepes) da Uesb. E-mail: <florisbete@gmail.com>.

** Doutorando pelo Programa de Pós-Graduação em Educação pela Universidade Estadual de Campinas (Unicamp)e Mestre pelo mesmo programa. Pesquisador do Grupo de Pesquisas em Políticas, Educação e Sociedade (GPPES) e do Grupo de Estudos e Pesquisa Diferenças e Subjetividades (DiS) da Unicamp. Docente da Faculdade Nossa Senhora de Lourde (FNSL). Professor efetivo da Rede Municipal de Ensino de Porto Seguro, Bahia. E-mail: $<$ leo.lacerda.campos@gmail.com>.
}

Práxis Educativa, Ponta Grossa, v. 17, e2219492, p. 1-19, 2022 Disponível em: <https://revistas2.uepg.br/index.php/praxiseducativa $>$ 
demonstram que as atividades publicadas na rede Pinterest são marcadas por estereótipos que significam as pessoas negras com os mesmos sentidos de séculos passados, legitimando a discriminação e a invisibilidade, frutos do racismo ainda vigente na sociedade brasileira.

Palavras-chave: Sentidos. Negro. Materiais didáticos.

\begin{abstract}
The purpose of this article was to analyze how the black person is signified in didactic activities developed for Elementary School students, exposed on the social network Pinterest, to be applied in classrooms, on the National Day of Black Awareness. The discussions were based on social theories that deal with Law no. 10. 639, of January 9, 2003, and racial issues. The theoretical contribution of analysis was the Enunciative Semantics of the Event, a semantic theory developed by Professor Eduardo Guimarães, who considers the study of enunciation as the place where meaning is historically constructed in the subject's relationship with language, in the event, and the text is seen as a complex unit of meaning that integrates utterances, which present in their functioning an internal consistency and a relative dependence, which give them meaning. The results of the analysis demonstrate that the activities published on the Pinterest network are marked by stereotypes that mean black people with the same meanings of past centuries, legitimizing discrimination and invisibility, fruits of racism still in force in the Brazilian society.
\end{abstract}

Keywords: Meanings. Black. Teaching materials.

Resumen: El objetivo de este artículo fue analizar cómo el negro es significado en actividades didácticas desarrolladas para alumnos/as de Educación Primaria, expuestas en la red social Pinterest, para ser aplicadas en las aulas, el Día Nacional de la Conciencia Negra. Las discusiones fueron fundamentadas en teorías sociales que abordan la Ley No 10. 639, de 9 de enero de 2003, y en temas raciales. El aporte teórico de análisis fue la Semántica Enunciativa del Acontecimiento, teoría semántica desarrollada por el profesor Eduardo Guimarães, que considera el estudio de la enunciación como el lugar donde el sentido se construye históricamente en la relación del sujeto con el lenguaje, en el acontecimiento, y el texto es visto como una unidad compleja de significación que integra enunciados, los cuales presentan una consistencia en su funcionamiento. y una dependencia relativa, que los hace significar. Los resultados del análisis demuestran que las actividades publicadas en la red Pinterest están marcadas por estereotipos que significan a las personas negras con los mismos sentidos de siglos pasados, legitimando la discriminación y la invisibilidad, frutos del racismo aún vigente en la sociedad brasileña.

Palabras clave: Sentidos. Negro. Materiales didácticos.

\title{
Introdução
}

No dia 9 de janeiro de 2003, foi criada a Lei $\mathrm{N}^{\circ}$ 10.639, que alterou a Lei $\mathrm{N}^{\circ}$ 9.394, de 20 de dezembro de 1996, Lei de Diretrizes e Bases da Educação Nacional (LDB), para incluir no Currículo Oficial da Rede de Ensino, nos estabelecimentos de Ensino Fundamental e Ensino Médio, oficiais e particulares, a obrigatoriedade do ensino de História e Cultura Afro-Brasileira (BRASIL, 2003a).

Por meio do artigo 26-A, acrescido à LDB $\mathrm{N}^{\circ}$ 9394/1996, ficou estabelecido que, no conteúdo de História e Cultura Afro-Brasileira, deverá ser incluído "[...] o estudo da História da África e dos Africanos, a luta dos negros no Brasil, a cultura negra brasileira e o negro na formação da sociedade nacional, resgatando a contribuição do povo negro nas áreas social, econômica e política pertinente à História do Brasil" (BRASIL, 2003a, p. 1). Foi determinado, também, que “[...] os conteúdos referentes à História e Cultura Afro-Brasileira serão ministrados no âmbito de todo o currículo escolar, em especial nas áreas de Educação Artística, Literatura e História Brasileira" (BRASIL, 2003a, p. 1).

Frente a essas questões, desenvolvemos uma análise de atividades didáticas relacionadas ao Dia Nacional da Consciência Negra, desenvolvidas para alunos/as dos anos iniciais do Ensino Fundamental, publicadas na rede social Pinterest. Essas atividades são utilizadas por um número

Práxis Educativa, Ponta Grossa, v. 17, e2219492, p. 1-19, 2022 
considerável de professores/as em sala de aula ${ }^{1}$. Selecionamos as atividades destinadas à aprendizagem acerca dos povos africanos e sua descendência, visando responder às seguintes questões: Que sentidos são construídos para o negro nessas atividades? Tais sentidos estão atrelados aos princípios norteadores da Lei $\mathrm{N}^{\circ} 10.639 / 2003$ ?

Analisarmos um texto a partir de um procedimento de análise que toma como base teórica a Semântica Enunciativa do Acontecimento, teoria desenvolvida por Eduardo Guimarães², é falarmos de um lugar que vê o texto como uma unidade de significação que está sempre nos interrogando e nos apontando caminhos para a descoberta de sentidos divididos, oriundos de lugares sociais diversos, atrelados a lugares de dizer também distintos. É compreendermos que um texto não é um mero conjunto de frases e parágrafos, mas uma "[...] unidade de sentidos que integra enunciados no acontecimento de enunciação" (GUIMARÃES, 2012, p. 25). Desse modo, cada atividade aqui analisada é tomada como um texto em que o funcionamento da língua, afetada pela exterioridade, produz sentidos.

Ressaltamos que a posição teórica de análise que assumimos não toma a língua como transparente, mas marcada pela opacidade e pela heterogeneidade. Assim, não existe um único sentido para a palavra ou enunciado, uma vez que a língua é tomada em sua relação com o mundo, com maneiras distintas de significar.

Nosso corpus consiste em três atividades, nas quais analisaremos os sentidos produzidos para o/a negro/a, mediante análise do funcionamento da língua, por meio do conceito de designação, uma relação linguística constituída de sentidos construídos no acontecimento, por meio da qual o real é significado na linguagem. Contudo, essa projeção não se dá de forma direta, sua produção ocorre pela relação entre as palavras, resultando na construção de sentidos. Esse real não é representável no seu todo, mas constituído como realidade diferente, projetada por determinada posição-sujeito na e pela enunciação.

\section{A Lei Federal No 10.639/2003 e sua aplicação na Educação Básica}

A Lei Federal No 10.639/2003 foi homologada 115 anos após a abolição da escravatura; isso demonstra o quão a abolição foi incipiente, no que concerne à inserção e/ou à integração social dos afro-brasileiros, principalmente no que diz respeito ao acesso à educação que, por sua vez, deveria oportunizar a equidade na valorização dos povos e de suas respectivas culturas, na formação do povo brasileiro, impedindo a valorização demasiada da cultura europeia, em detrimento da cultura indígena nativa e da africana, introduzida por meio do processo desumano da escravidão. Desse modo, podemos afirmar que, ao longo da tradição escolar, houve a negação das culturas indígenas e africanas e uma tentativa desenfreada de assimilação dos padrões europeus a serem seguidos, processo imposto desde o início da colonização. Nesse sentido, para Petronilha Beatriz Gonçalves e Silva:

$\mathrm{Na}$ experiência brasileira, além do que se passou com os indígenas, deve-se ter presente a situação dos africanos escravizados, de seus filhos e descendentes. A eles foi negada a possibilidade de aprender a ler, ou se lhes permitia, era com o intuito de incutir-lhes representações negativas de si próprios e convencê-los de que deveriam ocupar lugares

\footnotetext{
${ }^{1}$ Nossa vivência na escola pública de Educação Básica nos mostra que é comum, por parte de muitos/as professores/as, o uso de atividades retiradas desses sites, as quais já vêm prontas para imprimir.

2 Professor titular do Departamento de Linguística do Instituto de Estudos da Linguagem (IEL) e pesquisador do Laboratório de Estudos Urbanos (Labeurb) do Núcleo de Desenvolvimento da Criatividade (Nudecri) na Universidade Estadual de Campinas (Unicamp).
}

Práxis Educativa, Ponta Grossa, v. 17, e2219492, p. 1-19, 2022 Disponível em: <https:// revistas2.uepg.br/index.php/praxiseducativa $>$ 
subalternos na sociedade. Ser negro era visto como enorme desvantagem, utilizava-se a educação para despertar e incentivar o desejo de ser branco. (SILVA, 2007, p.495).

A implementação da Lei № 10.639/2003, sancionada pelo então presidente da República, Luiz Inácio Lula da Silva, atendeu às demandas apresentadas pelo Movimento Negro, dentre elas a necessidade urgente de implementar, nos currículos escolares, o Ensino de História e da cultura africana e afro-brasileira, tendo como premissa um giro epistemológico capaz de promover a valorização e a importância dos/as negros/as na formação econômica, cultural e social do Brasil. Para satisfazer tais exigências, foi necessária a realização da alteração da Lei $\mathrm{N}^{\circ}$ 9.394, de 20 de dezembro de 1996, que estabelece as Diretrizes e Bases da Educação Nacional (BRASIL, 1996). Para tanto, o Art. $1^{\circ}$ da Lei $\mathrm{N}^{\circ}$ 9.394/1996 passou a vigorar acrescido dos seguintes artigos: 26-A, 79-A e 79-B (BRASIL, 2003a).

No Art. 26-A, ficou determinado, como já afirmamos, que, nos estabelecimentos de Ensino Fundamental e Ensino Médio, oficiais e particulares, torna-se obrigatório o Ensino sobre História e Cultura Afro-Brasileira. Foram estabelecidos três parágrafos ${ }^{3}$; entretanto, o terceiro parágrafo foi vetado. O Art. 79-A também foi vetado ${ }^{4}$. Já o Art. 79-B determinou que o calendário escolar inclú́sse o dia 20 de novembro como o Dia Nacional da Consciência Negra (BRASIL, 2003a). Meses depois da sua promulgação, as preocupações voltaram-se para a necessidade de regulamentação da temática da História e Cultura Africana e Afro-Brasileira. Para esse fim, foi constituído, em abril de 2003, um grupo de trabalho formado por representantes do Conselho Nacional de Educação (CNE), do Ministério da Educação (MEC), da Comissão de Educação da Câmara dos Deputados e da Fundação Palmares, ligada ao Ministério da Cultura.

O trabalho realizado por esse grupo resultou na aprovação do Parecer CNE/CP No 3, de 10 de março de 2004, que versa sobre as Diretrizes Curriculares Nacionais para a Educação das Relações Étnico-Raciais e para o Ensino de História e Cultura Afro-Brasileira e Africana (BRASIL, 2004), regulamentando, assim, a alteração na LDB. A aprovação da Lei efetivou uma das propostas apresentadas pelo Movimento Negro, durante a Constituinte, reapresentada por Benedita da Silva, no momento da elaboração da LDB.

A Lei $\mathrm{N}^{\circ} 10.639 / 2003$, seus princípios e desdobramentos, mostram exigências de mudança de mentalidade, na maneira de pensar e de agir dos indivíduos, em particular, assim como das instituições e de suas tradições culturais, a partir dos seis eixos estratégicos propostos no documento "Contribuições para a Implantação da Lei 10.639/2003", a saber: "1) Fortalecimento do marco legal; 2) Política de formação para gestores e profissionais de educação; 3) Política de material didático e paradidático; 4) Gestão democrática e mecanismos de participação social; 5)

\footnotetext{
3 " $\int 1^{\circ} \mathrm{O}$ conteúdo programático a que se refere o caput deste artigo incluirá o estudo da História da África e dos Africanos, a luta dos negros no Brasil, a cultura negra brasileira e o negro na formação da sociedade nacional, resgatando a contribuição do povo negro nas áreas social, econômica e política, pertinentes à História do Brasil; $\int$ $2^{\circ}$ Os conteúdos referentes à História e Cultura Afro-Brasileira serão ministrados no âmbito de todo o currículo escolar, em especial nas áreas de Educação Artística e de Literatura e História Brasileira; \ 30 (VETADO)" (BRASIL, 2003a, p. 1).

${ }^{4}$ Art. 79-A, acrescido pelo projeto à Lei No 9.394/1996: “Art. 79-A. Os cursos de capacitação para professores deverão contar com a participação de entidades do movimento afro-brasileiro, das universidades e de outras instituições de pesquisa pertinentes à matéria”. Razões do veto: “O art. 79-A, acrescido pelo projeto à Lei no 9.394, de 1996, preceitua que os cursos de capacitação para professores deverão contar com a participação de entidades do movimento afrobrasileiro, das universidades e de outras instituições de pesquisa pertinentes à matéria. Verifica-se que a Lei no 9.394 , de 1996, não disciplina e nem tampouco faz menção, em nenhum de seus artigos, a cursos de capacitação para professores. O art. 79-A, portanto, estaria a romper a unidade de conteúdo da citada lei e, consequentemente, estaria contrariando norma de interesse público da Lei Complementar $n^{\circ} 95$, de 26 de fevereiro de 1998, segundo a qual a lei não conterá matéria estranha a seu objeto (art. 7o, inciso II)". (BRASIL, 2003b, n.p.).
}

Práxis Educativa, Ponta Grossa, v. 17, e2219492, p. 1-19, 2022 Disponível em: < https:// revistas2.uepg.br/index.php/praxiseducativa> 
Condições institucionais (financiamento, sensibilização e comunicação, pesquisa, equipes e regime de colaboração;) e 6) Avaliação e Monitoramento" (BRASIL, 2008, p. 26).

A obrigatoriedade de inclusão da História e Cultura Afro-brasileira e Africana nos Currículos da Educação Básica, sob decisão política, gerou fortes repercussões pedagógicas, inclusive no que diz respeito à formação de professores/as. Com a efetivação dessa medida, reconhece-se que, além de garantir vagas para negros/as nos bancos escolares, é preciso valorizar, devidamente, a história e a cultura de seu povo, buscando reparar danos à sua identidade e, inclusive, aos seus direitos.

As Políticas Públicas de Promoção da Igualdade Racial passaram a ter uma maior visibilidade por parte do Estado, por meio das orientações e das recomendações do plano de ação, aprovado e ratificado por mais de 150 países, na III Conferência Mundial Contra o Racismo, Discriminação Racial, Xenofobia e Intolerância Correlata, realizada no período de 31 de agosto a 7 de setembro de 2001, em Durban, África do Sul. Com os acordos firmados durante essa Conferência, o Brasil reconheceu a urgente necessidade de resgate dos valores civilizatórios africanos e das contribuições dos afro-brasileiros na formação do nosso povo.

Foi em meio a esse contexto que a Lei $\mathrm{N}^{\circ}$ 10.639/2003 foi homologada. Nesse sentido, faz-se necessário apresentar, neste artigo, algumas recomendações estabelecidas para um melhor encaminhamento na aplicabilidade de conteúdos que possam atender os princípios norteadores da referida Lei, ancorada, ainda, na formulação de uma proposta curricular acompanhada da História da África e dos Africanos, bem como da Luta dos Negros no Brasil, Cultura Negra Brasileira e o Negro na Formação da Sociedade Nacional, com a finalidade de estabelecer um novo olhar para os sujeitos envolvidos nos processos de ensino e de aprendizagem, por meio do resgate da contribuição do povo negro para a formação econômica, social, política e cultural.

Por séculos, o conhecimento de História e Cultura Africana e Afro-Brasileira foi negado e invisibilizado pela nossa educação, seja por meio dos currículos e/ou dos livros didáticos que insistiam em apresentar o Continente Africano em uma perspectiva negativa e homogênea, bem como a construção social do negro atrelada à escravidão ou à folclorização, como bem destaca Campos (2018):

Não podemos esquecer a maneira pela qual o Continente Africano foi projetado e introjetado nas mentalidades, através de ideologias bem elaboradas, que inferiorizavam os povos africanos e as suas respectivas culturas, tanto no colonialismo para justificar a escravidão, quanto neocolonialismo, para justificar a exploração da mão de obra e das riquezas minerais e naturais existentes no continente. (CAMPOS, 2018, p. 45).

Romper com os estereótipos construídos ao longo da história não é fácil, e o Ensino da História da África e da Cultura Afro-Brasileira busca reconhecer, valorizar e respeitar a cultura africana e afro-brasileira, servindo como um passo importante para o estabelecimento de um giro epistemológico capaz de promover a construção de novos paradigmas positivos. Nesse sentido, Maria de Lourdes Bandeira (2003) aponta a maneira pela qual as práticas e os valores culturais dos/as negros/as foram incorporados em nossa sociedade. Segundo a pesquisadora, esse movimento se deu por intermédio de uma "[...] produção nacional popular, reduzindo a diversidade dos afro-brasileiros à diferença racial, socialmente estigmatizada” (BANDEIRA, 2003, p. 144).

É importante compreendermos valores e lutas encabeçadas pela população negra para rompermos com séculos de sofrimento, especialmente por meio do processo de desqualificação desses sujeitos, na medida em que se deparam com o racismo presente nas "brincadeiras e apelidos" de cunho depreciativo a que o povo negro foi e ainda é submetido, levando em consideração os mecanismos de invisibilidade desses sujeitos e de sua cultura. Desse modo, o papel da escola é, ou

Práxis Educativa, Ponta Grossa, v. 17, e2219492, p. 1-19, 2022 Disponível em: <https:// revistas2.uepg.br/index.php/praxiseducativa $>$ 
pelo menos deveria ser, o espaço de contribuição para a inserção da história cultural, econômica, social e política, tanto dos/as africanos/as quanto dos/as afro-brasileiros/as, tendo em vista a importância do/a negro/a na construção e na edificação do Brasil.

A exposição de conteúdos que apresentem a história dos/as africanos/as e afrobrasileiros/as, por meio de um prisma positivo, vem romper com um paradigma educacional que por mais de cinco séculos se fez presente em nossos bancos escolares, valorizando única e exclusivamente a história eurocêntrica, em detrimento dos demais povos que foram responsáveis para a manutenção econômica do Brasil, desde a colônia, assim como as contribuições no campo cultural e social. Nesse bojo de reflexão, destacamos o pensamento da professora Petronilha Beatriz Gonçalves e Silva:

Somos oriundos de uma formação que atribui, aos brancos, aos europeus, a cultura que dizem clássica, pois permanece no tempo, desconhecendo-se culturas dos povos não europeus que também têm permanecido no tempo. Ignoramos, por exemplo, que os egípcios, povo também negro, ou melhor, os conhecimentos que eles produziram, estão no nascedouro da filosofia e das ciências o que se costuma atribuir aos gregos e a outros europeus. Somos levados a confundir cultura com ilustração, civilização com o hemisfério norte, ao lado de outros tantos equívocos. (SILVA, 2007, p.500).

É importante ressaltarmos os esforços realizados pelo MEC, sobretudo na elaboração das Diretrizes Curriculares Nacionais (DCN) para a Educação das Relações Étnico-Raciais, para dar conta da implementação da Lei $\mathrm{N}^{0}$ 10.639/2003. Além disso, destacamos o papel dos/as intelectuais, sobretudo negros/as, para a produção de artigos e livros que foram publicados desde a criação da referida Lei, servindo como alicerce para a formação inicial e continuada dos/as docentes, possibilitando a aquisição de conhecimentos específicos das temáticas a serem abordadas.

Ao longo da História brasileira, a educação escolar não soube dialogar com as diferenças étnico-raciais de nosso povo, uma vez que a escola tem se constituído em espaço de homogeneização, de negação da diferença e de institucionalização de experiências de discriminação e preconceito racial, desde os primeiros níveis da Educação Básica. Nessa perspectiva, Valdecir Nascimento (2003) nos alerta que as Escolas Públicas têm sido uma seara ativa, no que diz respeito "[...] à inferiorização das crianças e jovens negras/os, a partir dos estereótipos e estigmas que desestruturam a identidade e a autoestima desses alunos, desde os primeiros anos de estudos" (NASCIMENTO, 2003, p. 158).

Em consonância com tal pensamento, Anete Abramowicz, Fabiana Oliveira e Tatiane Rodrigues (2010, p. 86) afirmam que "[...] o preconceito e a discriminação, ainda que de forma escamoteada, são muito presentes na escola, e essa instituição, apesar de utilizar o discurso da igualdade, não respeita as diferenças". Dessa maneira, para que crianças negras obtenham um possível sucesso escolar, é preciso branquear-se. Nessa mesma linha de raciocínio, Nilma Lino Gomes (2003, p. 72) assinala que a escola precisa “[...] ressignificar sua prática pedagógica de acordo com as profundas mudanças ocorridas nos últimos anos", para garantir "[...] uma educação escolar democrática, inclusiva e de qualidade".

A educação constitui-se como um dos principais mecanismos ativos de transformação de um povo, se levarmos em consideração o papel da escola, de forma democrática e comprometida com a formação do ser humano, na sua integralidade, estimulando a formação de valores, hábitos e comportamentos que respeitem as diferenças e as características próprias de grupos distintos. $\mathrm{O}$ desafio lançado, a partir do estabelecimento da Lei $\mathrm{N}^{\circ} 10.639 / 2003$, deu-se, justamente, na medida em que ocorreu a necessidade, sobretudo, de torná-la conhecida, respeitada e cumprida, com a finalidade da sua efetivação, nas escolas, possibilitando aos/às alunos/as discussões que contemplem a História da África e da Cultura Afro-Brasileira.

Práxis Educativa, Ponta Grossa, v. 17, e2219492, p. 1-19, 2022 Disponível em: <https:// revistas2.uepg.br/index.php/praxiseducativa $>$ 
Percebemos que, mesmo diante da existência da legislação antirracista, embora indique conquistas, ela não garante a efetiva execução de práticas educacionais que contemplem as necessidades específicas dos estudantes negros/as nos ambientes escolares do país. Parte dos profissionais da educação, ao trabalharem conteúdos ligados à África, não reconhece a importância da cultura africana na formação do povo brasileiro, e tende a enfatizar os estudos voltados à escravidão. Por isso, faz-se necessária a formação continuada de professores/as, a fim de garantir, nesse movimento educacional, o protagonismo do povo negro, para que possamos transformar o nosso paradigma educacional de tal modo que nos prepare para o enfrentamento e combate da perpetuação dos estereótipos, bem como do racismo estrutural que se manifesta no contexto escolar.

Em certo sentido, a escola brasileira, ao ser indagada pelo Movimento Negro, em relação à implementação de uma educação antirracista, vive uma situação de tensão entre configurar-se, de fato, como um direito social para todos e, ao mesmo tempo, respeitar e reconhecer as diferenças. Ao assumir essa dupla função, a escola brasileira, desde a Educação Básica até o Ensino Superior, é responsável por construir práticas, projetos e iniciativas eficazes de combate ao racismo e de superação das desigualdades raciais. Diante de tantos desafios, os/as educadores/as brasileiros/as, de qualquer pertencimento étnico-racial, estão convocados/as a construir novas posturas e práticas pedagógicas e sociais. Dentre elas, destacamos o desenvolvimento de uma inquietude epistemológica e política, o inconformismo diante das desigualdades e aposta nos processos de emancipação social (GOMES, 2007).

\section{Semântica Enunciativa do Acontecimento: nosso aporte teórico de análise}

A Semântica Enunciativa do Acontecimento, desenvolvida pelo professor Eduardo Guimarães e sua equipe de pesquisa, é uma construção teórica que designa a enunciação como um acontecimento sócio-histórico, em que se dá a relação do sujeito com a língua, e deve acontecer em um espaço em que haja possibilidade de se pensar como o sentido se constitui historicamente (GUIMARÃES, 2005, 2007a).

Quando enunciamos (falamos, escrevemos), instaura-se o acontecimento de enunciação; esse acontecimento do dizer é o responsável por instalar uma temporalidade, ou seja, o dizer traz para o presente da enunciação um memorável, que não é uma lembrança individual, mas rememoração de enunciações que apontam para uma latência de futuro, compreendida como as diversas possibilidades de interpretação (GUIMARÃES, 2005).

Para melhor compreender essa questão, tomemos o enunciado Dia Nacional da Consciência Negra ${ }^{5}$, o qual recorta diversos memoráveis, dentre os quais podemos destacar: o memorável da diáspora africana, da história dos/as africanos/as e seus descendentes no Brasil, do modo como foram escravizados/as e invisibilizados/as; o memorável da resistência, da luta desse povo contra o sistema opressor e racista; o memorável da contribuição dos/as africanos/as e seus descendentes na constituição e na construção da sociedade brasileira, em todas as áreas: social, política, econômica, científica, cultural, educacional; o memorável da luta que ainda persiste na sociedade brasileira, contra toda forma de discriminação, contra as desigualdades e pela superação do racismo. Nesse sentido, esses memoráveis não são lembranças, mas acontecimentos históricos e políticos marcados pelo embate, pela luta em prol do direito de dizer e ser ouvido, de ocupar espaços que, por séculos, destinam-se a uma minoria branca privilegiada.

\footnotetext{
${ }^{5}$ Utilizaremos o itálico não apenas para destacar palavras estrangeiras, mas também para destacar enunciados em análise.
}

Práxis Educativa, Ponta Grossa, v. 17, e2219492, p. 1-19, 2022 
Por ser constituído por esse passado de sentidos relacionado com o presente, o acontecimento faz com que os enunciados, entendidos como elementos que integram um texto e que significam para além das situações empíricas, tenham significados diferentes. No acontecimento, os sentidos significam algo do real, formam-se e transformam-se em outros sentidos, dividem-se, entram em conflito, e é essa situação conflituosa que o torna político (GUIMARÃES, 2005). Desse modo, o enunciado Dia Nacional da Consciência Negra, ao relacionarse com outros enunciados em um texto, pode apresentar sentidos divididos, diferentes.

Para a Semântica Enunciativa do Acontecimento, os sujeitos/falantes não são indivíduos, eles são determinados pelas línguas que falam, são autorizados a dizer certas coisas e não outras, a poder falar de certos lugares sociais e não de outros. Assim, tornam-se uma figura política ao assumir a palavra, por estarem constituídos pelos espaços de enunciação, que não são espaços físicos, mas espaços políticos. O político, aqui, é entendido com "[...] algo que é próprio da divisão, que afeta materialmente a linguagem, o acontecimento da enunciação" (GUIMARÃES, 2005, p. 16). Ele é o "[...] fundamento das relações sociais, no que tem importância central a linguagem" (GUIMARÃES, 2005, p. 16). Ademais, o autor acrescenta que o político é "[...] caracterizado pela contradição de uma normatividade que estabelece (desigualmente) uma divisão do real e a afirmação de pertencimento dos que não estão incluídos"; ele é "[...] um conflito entre uma divisão normativa e desigual do real e uma redivisão pela qual os desiguais afirmam seu pertencimento" (GUIMARÃES, 2005, p. 16). Esse embate de forças ocorre porque os espaços de enunciação "[...] são espaços habitados por sujeitos divididos por seus direitos de dizer e aos modos de dizer" (GUIMARÃES, 2005, p. 18). São espaços de conflito, onde os papéis sociais dos sujeitos são redivididos. Nesse sentido, enunciar é estar na língua em funcionamento, no acontecimento e pelo acontecimento.

Os modos específicos de acesso à palavra são constituídos pela cena enunciativa, um espaço particular, onde os lugares de enunciação no acontecimento são distribuídos. Esses lugares "[...] são configurações específicas do agenciamento enunciativo para aquele que fala e aquele para quem se fala, que não são pessoas donas do seu dizer, mas lugares constituídos pelos dizeres" (GUIMARÃES, 2005, p. 23). Tais lugares são representados pelo Locutor (com L maiúsculo), responsável pelo dizer, pelo locutor $x$ (com 1 minúsculo), lugar social autorizado a falar, e pelo enunciador, identificado pelo lugar de onde se diz algo e designado como enunciador individual, enunciador genérico, enunciador coletivo e enunciador universal.

O enunciador-individual aparece como aquele que imagina "[...] que está acima de todos, independente da história" (GUIMARÃES, 2005, p. 25). O genérico é a representação de um coletivo. O dizer não é só seu, é de todos, por isso ele se torna uma parte da coletividade. Todavia, "[...] se mostra como um indivíduo que escolhe falar tal como outros indivíduos, outra forma de se apresentar como independente da história" (GUIMARÃES, 2005, p. 25). O enunciadoruniversal enuncia de um lugar tido como sendo verdadeiro ou falso, próprio do dizer científico, apesar de não ser exclusividade dele. Também apresenta um lugar de dizer "[...] não social, acima da história, de onde se diz sobre o mundo" (GUIMARÃES, 2005, p. 26). Já o enunciador-coletivo representa a vOz de todos como uma única voz, está "[...] ligado a um lugar, diríamos, corporativo, de um conjunto, que o dizer apresenta como um todo específico" (GUIMARÃES, 2013, p.193).

Nessa configuração da cena enunciativa, “[...] o Locutor só pode falar enquanto predicado por um lugar social ao que chamaremos de locutor x; onde o locutor (com minúscula) sempre vem predicado por um lugar social que a variável x representa (presidente, governador, etc.)" (GUIMARÃES, 2005, p. 24). Quando o/a professor/a faz uma exposição acerca do Dia Nacional da Consciência Negra, apresentando informações históricas para os/as alunos/, por exemplo, ele fala do lugar social de locutor-historiador. O dizer desse locutor-historiador ancora-se em um ou

Práxis Educativa, Ponta Grossa, v. 17, e2219492, p. 1-19, 2022 Disponível em: < https:// revistas2.uepg.br/index.php/praxiseducativa $>$ 
mais enunciadores (individual, genérico, coletivo, universal), lugares enunciativos produzidos pela língua em funcionamento.

Guimarães $(1989,2005,2018)$ utiliza vários procedimentos de análise para explicar o funcionamento da língua no texto e as relações de sentido que são historicamente constituídas nesse processo. Utilizamos, aqui, os procedimentos de reescrituração e articulação, a partir dos quais foram identificadas e analisadas as relações de designação.

A reescrituração é “[...] o procedimento pelo qual a enunciação de um texto rediz insistentemente o que já foi dito, fazendo interpretar uma forma como diferente de si”. É a reescrituração que "[...] coloca em funcionamento uma operação enunciativa fundamental na constituição de sentido de um texto" (GUIMARÃES, 2007b, p. 84). A essa operação dá-se o nome de predicação, não a da sentença, mas aquela em que, "[...] no fio do dizer, uma expressão se reporta a outra, pelos mais variados procedimentos, dentre eles a repetição, a substituição, a elipse, a expansão, e a condensação" (GUIMARÃES, 2007b, p. 84).

Ross:

Para melhor compreensão desse procedimento, teceremos análise do texto de Rosemary de

\section{Hoje na História, 20 de novembro - Dia Nacional da Consciência Negra}

O Dia Nacional da Consciência Negra homenageia e resgata as raízes do povo afrobrasileiro e é comemorado no Brasil no dia 20 de novembro. Esta data foi restabelecida pelo projeto lei número 10.639 , no dia 9 de janeiro de 2003, porque coincide com o dia 20 de novembro de 1695, dia da morte de Zumbi dos Palmares, grande líder da resistência negra e da luta pela liberdade, autor da célebre frase: "Nascer negro é conseqüência, ser negro é consciência". Este dia é dedicado de modo especial à reflexão sobre a inserção do negro na sociedade brasileira e sobre a influência do povo africano na formação cultural do nosso país. Desde o Brasil colônia até a atualidade as influências dos negros africanos foram muitas, sobretudo nos aspectos religiosos, políticos, sociais e gastronômicos. Ao longo da nossa história, as crenças, as danças, o vocabulário, a culinária, o folclore e tantas outras coisas, foram sendo incorporadas à nossa cultura. (ROSS, 2012, n. p.).

O Locutor, nessa cena enunciativa, fala do lugar-social de locutor-historiador. O título do texto [Hoje na História, 20 de novembro - Dia Nacional da Consciência Negra] é uma reescrituração por condensação, já que resume a ideia apresentada pelo locutor em todo o texto. Após o título, os enunciados que dão continuidade ao texto caracterizam a reescrituração por expansão, uma vez que o locutor amplia o já dito, trazendo informações sobre o dia 20 de novembro, bem como o porquê desse dia ser significado como o Dia Nacional da Consciência Negra. As formas linguísticas esta data e este dia reescrituram por substituição o 20 de novembro que, por sua vez, é reescriturado pela repetição[(...) é comemorado no Brasil no dia 20 de novembro; porque coincide com o dia 20 de novembro de 1695 (...)], para dar ênfase à importância da escolha desse dia para homenagear o povo africano e sua descendência, por ser o dia em que morreu um dos maiores líderes de resistência negra no Brasil. Há, também, uma reescrituração por elipse dessa expressão linguística no advérbio boje, que inicia o título do texto. Uma outra forma de reescrituração por substituição é a que se estabelece por sinonímia, quando, por exemplo, Zumbi dos Palmares é reescriturado por grande líder.

É importante ressaltarmos que a reescrituração não está atrelada apenas ao funcionamento sintático, ela também depende das relações de sentido que são historicamente constituídas. Assim, a reescrituração liga elementos de um texto com outros inseridos no mesmo texto, e ao retomar um elemento, este já não apresenta o mesmo sentido.

Práxis Educativa, Ponta Grossa, v. 17, e2219492, p. 1-19, 2022 Disponível em: <https:// revistas2.uepg.br/index.php/praxiseducativa $>$ 
No que diz respeito ao procedimento de articulação, Guimarães (2009) afirma que as relações semânticas são estabelecidas pela forma como os elementos linguísticos dão sentido a outros elementos em sua proximidade, mediante agenciamento enunciativo. Ela pode ocorrer de três modos distintos: por dependência, por coordenação e por incidência. $\mathrm{Na}$ articulação por dependência, “[...] os elementos contíguos se organizam por uma relação que constitui, no conjunto, um só elemento" (GUIMARÃES, 2009, p. 51), como podemos ver em: raízes do povo, em que povo se vincula a raízes, constituindo uma única unidade. $\mathrm{Na}$ articulação por coordenação, há uma tomada de elementos que são organizados “[...] como se fossem um só da mesma natureza de cada um dos constituintes" (GUIMARÃES, 2009, p.51), a exemplo de: as crenças, as danças, o vocabulário, a culinária, o folclore e tantas outras coisas, foram sendo incorporadas à nossa cultura: $\mathrm{Na}$ articulação por incidência, ocorre uma relação "[...] entre um elemento da mesma natureza e outro de outra natureza, de modo a formar um novo elemento do tipo do segundo" (GUIMARÃES, 2009, p.51). Um exemplo seria dizer: Até mesmo em um país de maioria negra a luta desse povo pelo direito de ouvir e ser ouvido não para, em que o até mesmo produz o sentido de avaliação, uma vez que "[...] sustenta uma posição, fala da enunciação de um enunciado que enuncia” (GUIMARÃES, 2018, p. 83).

A designação é uma relação linguística constituída de sentidos construídos no acontecimento, por meio da qual o real (o existente) é significado na linguagem, mas essa projeção não se dá de forma direta, sua produção ocorre mediante relação entre as palavras, resultando na construção de sentidos. Pela designação, os nomes são significados, mas não enquanto algo abstrato. Essa significação ocorre mediante a relação linguística simbolicamente remetida ao real, tomada na história. Desse modo, um nome é designado não a partir do seu sentido denotativo, mas pela relação de sentidos que ele estabelece com outros nomes, em um acontecimento enunciativo (GUIMARÃES, 2005).

Se analisarmos o nome que Rosemary de Ross dá a seu texto [Hoje na História, 20 de novembro - Dia Nacional da Consciência Negra], sem uma ligação com um acontecimento histórico, é possível dizer que ele representa apenas uma data, um dia comemorativo. Contudo, essa nomeação aponta para sentidos funcionando em outra direção, os quais indicam que ele está ligado a um acontecimento político constituído por sentidos que apontam lugares sociais marcados pela luta, pela resistência. Essas relações de sentido constituem o Domínio Semântico de Designação (DSD), o procedimento que explica como funciona o sentido da palavra no texto, mediante a relação enunciativa que ela mantém com outras palavras, ali também funcionando. Para dizer o sentido de uma palavra, é necessário estabelecer o seu DSD. Para isso, é preciso se atentar para o funcionamento da palavra no texto em que ela aparece, suas relações com as outras palavras que ali estão, pois são essas relações que constituem o seu sentido (GUIMARÃES, 2005, 2007b).Frente a essas discussões, passemos agora à análise do nosso corpus.

\section{O corpus em análise}

Nosso corpus consiste em três atividades elaboradas para os anos iniciais do Ensino Fundamental, publicadas na rede social Pinterest, as quais foram pesquisadas por meio do seguinte enunciado de busca, no Google: Atividades para o Dia Nacional da Consciência Negra, para imprimir. A primeira delas(Figura 1) solicita a alunos e alunas que façam uma relação entre palavras que representam a contribuição dos negros para a formação da nossa cultura e dos nossos costumes. Vejamos: 
Figura 1 - Atividade 1

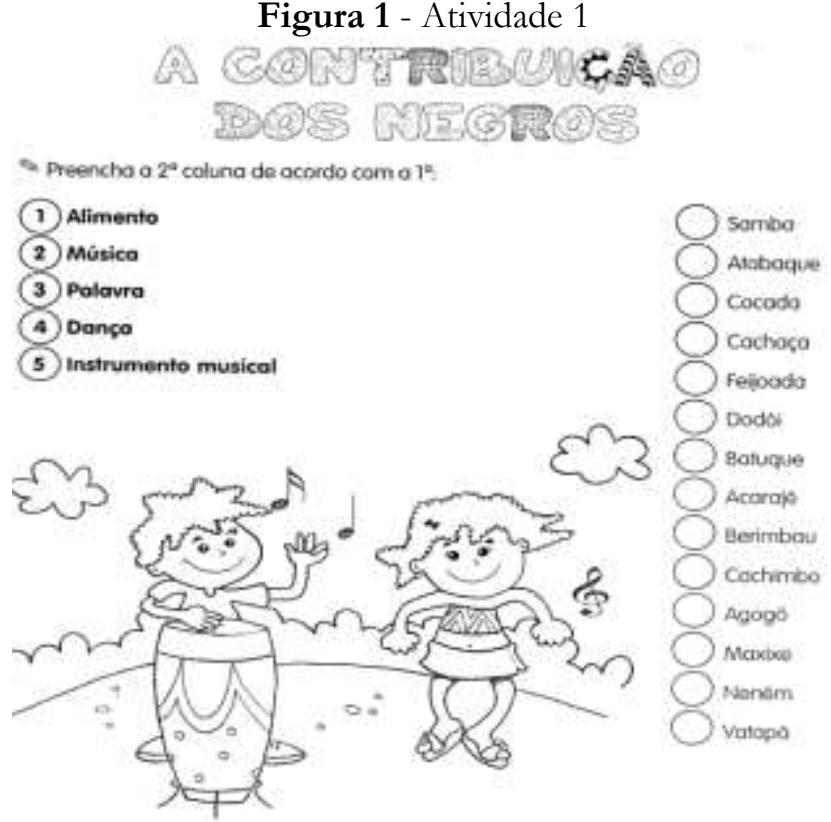

Os negros contribuiram muito para a formaçáo da nossa cultura e de nossos costumes.

Fonte: Imagem extraída de Pinterest. ${ }^{6}$

A atividade intitulada $A$ Contribuição dos Negros traz palavras que constroem sentidos sobre a contribuição dos povos negros para a formação da cultura e dos costumes da sociedade brasileira. O Locutor fala a partir de dois lugares sociais: o lugar do locutor-docente, no dizer que determina o que deve ser realizado pelo/a aluno/a [Preencha a $2^{a}$ coluna de acordo com a $1^{\mathrm{q}}$ ], e o lugar de locutorhistoriador, quando apresenta as informações acerca das contribuições dos negros em nosso país. O locutor-historiador mobiliza o enunciador-universal para dizer que elementos se caracterizam como contribuição das pessoas negras para a nossa cultura e os nossos costumes. Essa contribuição está reescriturada pelos elementos que compõem tanto a primeira quanto a segunda coluna [alimento, palavra, música, dança e instrumento musical); (samba, atabaque, cocada, cachaça, feijoada, dodói, batuque, acarajé, berimbau, cachimbo, agogô, maxixe neném, vatapá.]. A coluna da esquerda está ligada a elementos da coluna da direita, por meio de uma reescrituração por enumeração, em que esses elementos se acumulam, construindo sentidos para o que se configura como contribuições.

Para melhor compreender tais sentidos, analisemos o seguinte DSD:

${ }^{6}$ Disponível em: https://br.pinterest.com/pin/816699713660483747/. Acesso em: 8 dez. 2021.

Práxis Educativa, Ponta Grossa, v. 17, e2219492, p. 1-19, 2022 Disponível em: < https:// revistas2.uepg.br/index.php/praxiseducativa $>$ 


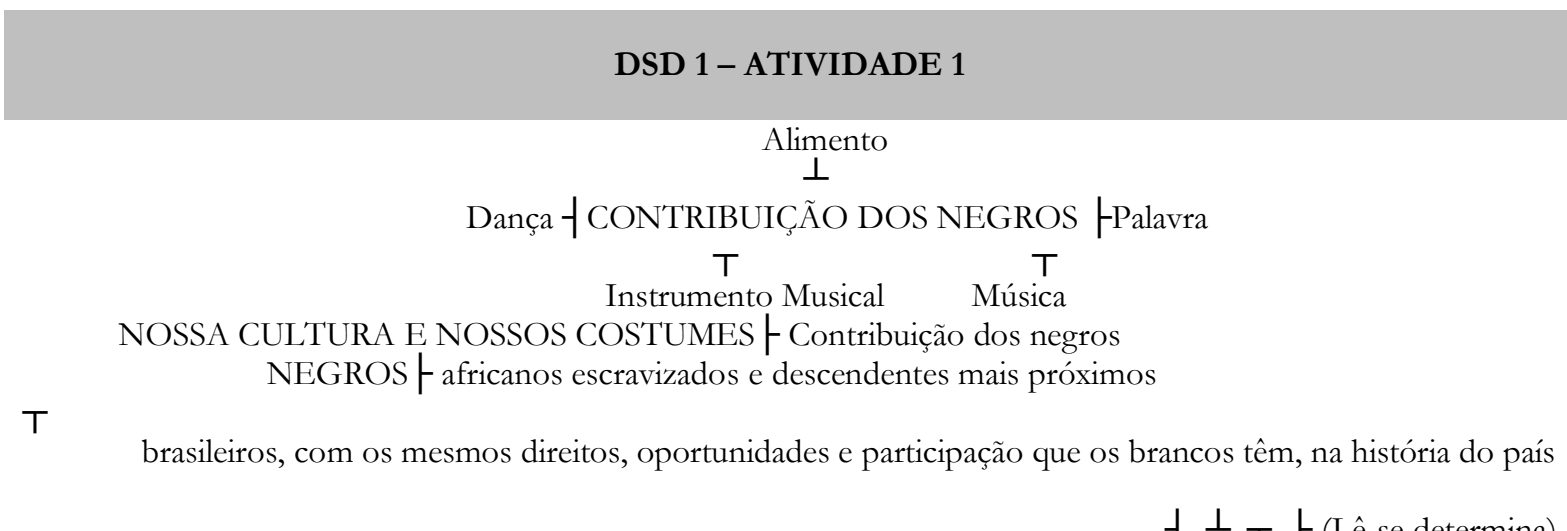

$\dashv, \perp, T, \vdash$ (Lê-se determina)

Nas relações instauradas no DSD1, os sentidos construídos para negros os significam como pessoas cuja contribuição determina a cultura e os costumes de todos nós que compomos a sociedade brasileira, o que pode ser ratificado pelo uso dos pronomes possessivos, nossa e nossos. Outra questão é que o funcionamento do verbo contribuir, no pretérito perfeito [contribuiram],constrói sentidos divididos, a partir dos seguintes memoráveis: negros são os/as africanos/as que foram escravizados/as e seus descendentes mais próximos; o povo da diáspora africana agora atua na formação da nossa cultura e dos nossos costumes não como negros, mas como brasileiros mestiços. Esse último memorável recorta outro, atrelado à ideologia da democracia racial, política de branqueamento com o discurso de uma igualdade mascarada que fortalece as desigualdades.

Seguindo a análise, a contribuição dos negros é apresentada de forma limitada, uma vez que é determinada por apenas cinco elementos: dança, alimento, palavra, instrumento musical, música. Essa determinação encaminha para sentidos de que essa contribuição se resume a um saber popular, invisibilizando as contribuições dessas pessoas em outras áreas do conhecimento, a exemplo de pesquisadores/as, artistas, escritores/as, cientistas, grandes líderes de movimentos políticos, dentre outros, cuja participação na construção da história do Brasil não pode ser negada.

Esses sentidos que se relacionam na enumeração dos cinco elementos e das palavras a eles atrelados [alimento, palavra, música, dança e instrumento musical; samba, atabaque, cocada, cachaça, feijoada, dodói, batuque, acarajé, berimbau, cacbimbo, agogô, maxixe neném, vatapá.], recortamos seguintes memoráveis: o memorável de que negro/a só tem competência para cozinhar determinados alimentos, dançar samba e maxixe, cantar músicas e tocar instrumentos específicos; o memorável do racismo epistêmico, o qual cria obstáculos para que intelectuais negros/as possam ser ouvidos/as, para que suas produções sejam lidas e discutidas, apagando, desse modo, sua participação e de demais pessoas negras em espaços de debate e de atuação política.

O movimento dos sentidos na atividade analisada aponta o quanto as discussões de Lélia Gonzalez (1984) são atuais, quando ela afirma que os espaços para negras e negros ainda são interditados nas academias e nos meios científicos, tendo suas vozes silenciadas, sendo colocados/as, como afirma, na parte de trás das mesas de discussões acerca de si mesmos/as. E alguns docentes, como podemos identificar nessa atividade desenvolvida para ser aplicada em sala de aula, reiteram esse silêncio, uma vez que atividades que propõem a alunos e alunas continuam projetando sentidos que fortalecem a discriminação e dificultam a afirmação do respeito, da valorização e da autoestima, tão importantes na luta contra o racismo.

Passemos, agora, para a segunda atividade (Figura 2).

Práxis Educativa, Ponta Grossa, v. 17, e2219492, p. 1-19, 2022 
Figura 2 - Atividade 2

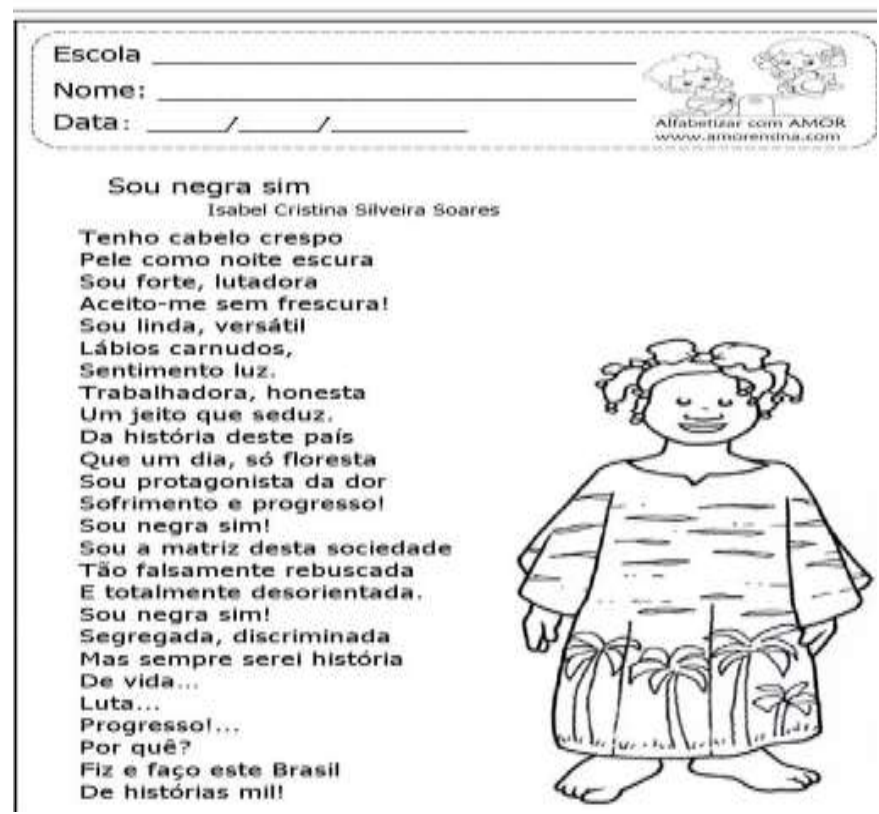

Fonte: Imagem extraída de Pinterest. ${ }^{7}$

Nessa atividade, o Locutor fala do lugar social de locutor-poeta-negra, por meio da mobilização de diferentes enunciadores. Em primeiro plano, é apresentado o enunciadorindividual, de onde se diz para o alocutário-leitor, mediante utilização de adjetivos funcionando como uma reescrituração por substituição, quem é esse locutor-poeta, que sentidos ele constrói para si mesmo (negra, forte, lutadora, linda, trabalhadora, honesta etc.) e como ele se vê na história deste país (protagonista da dor, matriz da sociedade, segregada, discriminada). É também ancorado no enunciadorindividual que o locutor apresenta os seus sinais diacríticos [cabelos crespos, pele como noite escura].

O locutor também diz de um lugar que se significa como coletivo, no texto como um todo, uma vez que inscreve, nos fios do dizer, outras mulheres negras que se identificam com os conflitos e com a luta pelo pertencimento e pelo objeto do dizer que aí se apresentam, por meio da utilização de uma reescrituração por elipse (EU), marcada pelo verbo na primeira pessoa do singular [tenho, sou, serei, fiø], a qual possibilita a mobilização de lugares sociais, pois, quando realiza a leitura do texto, o alocutário-leitor o lê como locutor-poeta-negra.

Há sentidos, no texto, que apontam para o movimento de resistência, aqui tomado não como um movimento intencional, mas como uma quebra de ritual, uma transgressão de fronteiras em que "[...] uma série heterogênea de efeitos individuais entra em ressonância e produz um acontecimento histórico, rompendo o círculo de repetição" (PÊCHEUX, 1990, p. 17). Uma resistência que é resultado de uma falha na estrutura do Estado, a qual provoca a falta de instituições, de políticas, de oportunidades para todos/as. Essa falta produz divisões, exclusões, ao mesmo tempo em que pode provocar a submersão na falta ou então a resistência. Assim, “[...] o sujeito não resiste por 'mágica', ou por voluntarismo, mas por condições que abrem para ele um espaço politicamente significado em que os sentidos podem ser outros" (ORLANDI, 2015, p. 192).

Assim sendo, há um gesto de resistência nos seguintes enunciados de autoafirmação: Sou forte, lutadora! Sou linda, versátil! Sou negra sim! Mas sempre serei história de vida... luta... progresso. No primeiro enunciado, o dizer instaura o embate contra as formas de opressão existentes em nosso país, enfrentadas diariamente por negras e negros que lutam para ocupar espaços que the são

7 Disponível em: https://br.pinterest.com/pin/643803709214282948/. Acesso em: 8 dez. 2021.

Práxis Educativa, Ponta Grossa, v. 17, e2219492, p. 1-19, 2022 Disponível em: <https://revistas2.uepg.br/index.php/praxiseducativa> 
negados; no segundo, há um gesto de resistência em relação aos estereótipos construídos para corpos que não são aceitos pelos padrões de beleza estabelecidos na sociedade, e o corpo negro é um dos que se inserem nessa lista de exclusão; no terceiro enunciado, a resistência está presente na autodefinição, no orgulho demonstrado por ser negra, na autoestima que tem se tornado um gesto político na luta contra o racismo; e no quarto enunciado, a resistência se dá quando o locutor demonstra que a luta ainda não terminou, como podemos identificar no advérbio sempre, que a sua história de vida não pode ser vista apenas como uma existência conformista, passiva, mas uma existência política, de luta e de conquistas (progresso) diante dos conflitos em prol do pertencimento e do direito à voz.

Observemos outras relações de sentido no seguinte DSD:

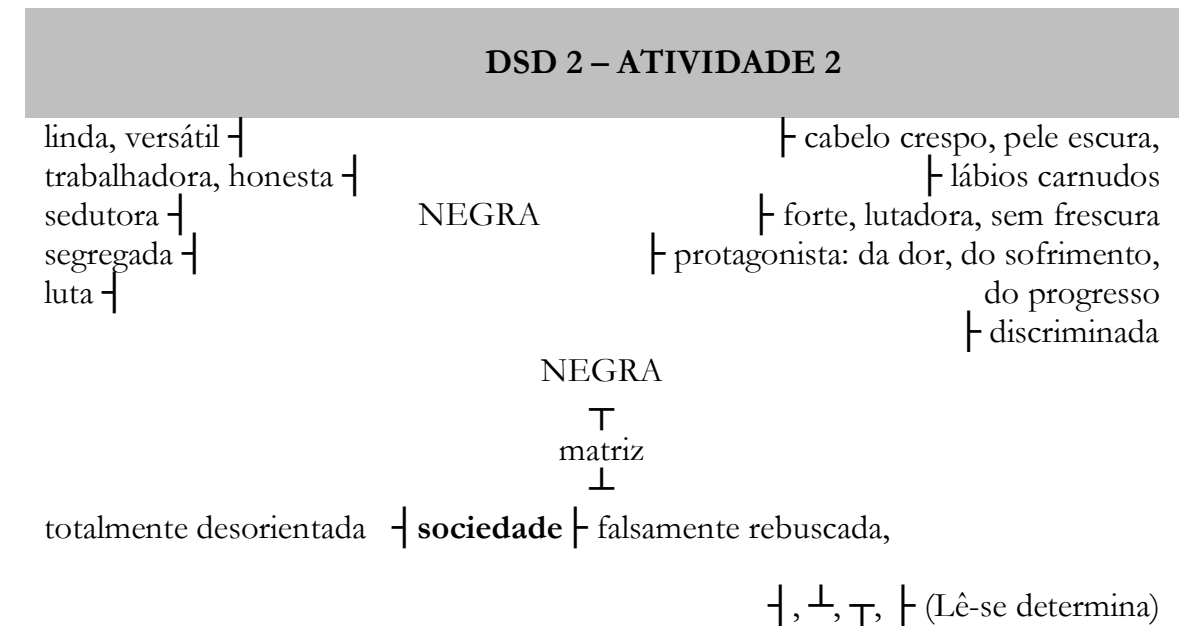

$\mathrm{Na}$ designação de negra, apresentada no DSD, estão postos sentidos divididos. Primeiro, os sentidos construídos para o corpo da mulher negra a posiciona em um lugar que estabelece que existem características físicas determinadas para a identificação do negro: cabelo crespo, pele escura, lábios carnudos. Assim sendo, nesse lugar de dizer, quem não tem essas marcas diacríticas são os denominados morenos, mulatos, pardos, mestiços, brancos, o que demonstra que o locutorpoeta está afetado pela política de branqueamento racial que tem barrado, segundo Abdias Nascimento (2019), as possibilidades de autoafirmação do povo negro, negando-lhe o direito de viver com integridade, tendo orgulho e respeito por sua identidade. Os morenos, mulatos, pardos, mestiços estão na fronteira entre o branqueamento e o enegrecimento, como afirma Nilma Lino Gomes (2019), e estar nessa fronteira, diz a autora, provoca a ilusão de que o corpo está constituído por outros sentidos que o tiram do alvo das práticas racistas, mas é um engano, porque ele está tão envolvido nos conflitos quanto o corpo marcado com sinais diacríticos como cabelos crespos, lábios carnudos, pele retinta.

Seguindo a análise, os sentidos construídos pelas designações trabalhadora e honesta apontam uma crítica a práticas sociais que posicionam pessoas negras no lugar da ociosidade, da preguiça, da desonestidade. Essa relação de sentidos traz para o presente do acontecimento o memorável de acontecimentos diários em nosso país, em que pessoas negras são discriminadas, e/ou assassinadas, sob a justificativa de que são vagabundas, preguiçosas, marginais. Nesse sentido, o grito "somos trabalhadores honestos" parece se tornar, cada vez mais, tanto um lamento por vidas perdidas quanto uma voz de resistência na luta para que o genocídio negro tenha um fim.

O DSD também aponta que no texto há sentidos que constroem para a mulher negra a imagem da sedução. Ela é uma mulher linda, versátil, sedutora, com lábios carnudos, recortando o memorável do estereótipo da sensualidade do corpo negro, transformado em objeto de fetiche

Práxis Educativa, Ponta Grossa, v. 17, e2219492, p. 1-19, 2022 Disponível em: < https:// revistas2.uepg.br/index.php/praxiseducativa $>$ 
sexual. Também é recortado o memorável de que as mudanças realizadas no corpo e no cabelo, por parte de algumas pessoas negras, estão relacionadas ao que se denomina mimimi, e não ao medo de ser discriminada pela sociedade [Aceito-me sem frescura!]. Outro memorável recortado é o da escravização enfrentada pelos povos negros no início da colonização do Brasil e o do sistema opressor que ainda se impõe sobre esse povo, desde o pós-abolição, sentidos estes postos em protagonista da dor, do sofrimento; segregada, discriminada. Nesse sentido, trazemos aqui as considerações de Campos (2018) acerca de que a abolição está malsucedida, uma vez que não criou as bases concretas para a inserção e/ou integração dos ex-escravizados na sociedade brasileira, uma vez que o próprio Estado implementa uma série de medidas a fim de consolidar a política de branqueamento, a exemplo do próprio financiamento da imigração europeia que tinha como finalidade o estabelecimento de um processo de miscigenação e de branqueamento.

A relação de sentidos no texto traz, também, o memorável das organizações sociais e políticas nos quilombos, seja nos "[...] movimentos de insurreições, levantes, revoltas armadas proclamando a queda do sistema escravo [...]", resistindo à opressão e à chibata, "[...] africanos orgulhosos de sua liberdade e dignidade humana" (NASCIMENTO, 2019, p. 50); dos movimentos sociais protagonizados por mulheres negras e homens negros que fizeram e continuam fazendo das ruas espaços de educação e de luta, denunciando o racismo e a opressão. Esse memorável está recortado nos sentidos postos em Luta...

Ainda podemos observar, nas relações demonstradas no DSD, sentidos que se contrapõem, ao serem constituídos para a mulher negra. Isso pode ser identificado quando temos mulher negra sendo determinada por matriz, que, por sua vez, determina a sociedade brasileira, esta determinada por totalmente desorientada e falsamente rebuscada. O modo como a língua está funcionando nessas designações significa a mulher negra de outra forma: como a palavra matriz se apresenta nesse dizer como origem da sociedade brasileira, o sentido aponta que há uma falha nessa matriz, ou seja, há uma falha no povo negro que essa mulher representa, uma vez que o resultado da sua criação, a sociedade, é marcado pela falsidade e pela desorientação.

A terceira e última atividade (Figura 3) consiste em uma proposta de pintura e apresentação da palavra IGUALDADE como palavra-chave. Antes de analisá-la, é importante pensarmos em um memorável que é recortado quando falamos de negros/as no Brasil. Pessoas oriundas de casamentos inter-raciais em nosso país são identificadas pela maioria do povo brasileiro e por alguns documentos oficiais como pardas, morenas ou mulatas, não negras. Os/as negros/as são identificados/as por essas pessoas e/ou documentos por sinais diacríticos como: cabelos crespos, pele retinta, lábios carnudos. Nesse sentido, na imagem que segue é possível dizer que o menino negro é o que está abaixado, com os joelhos sobre a terra. Vejamos:

Práxis Educativa, Ponta Grossa, v. 17, e2219492, p. 1-19, 2022 
A significação do negro em materiais didáticos: uma análise semântica ...

Figura 3 - Atividade 3

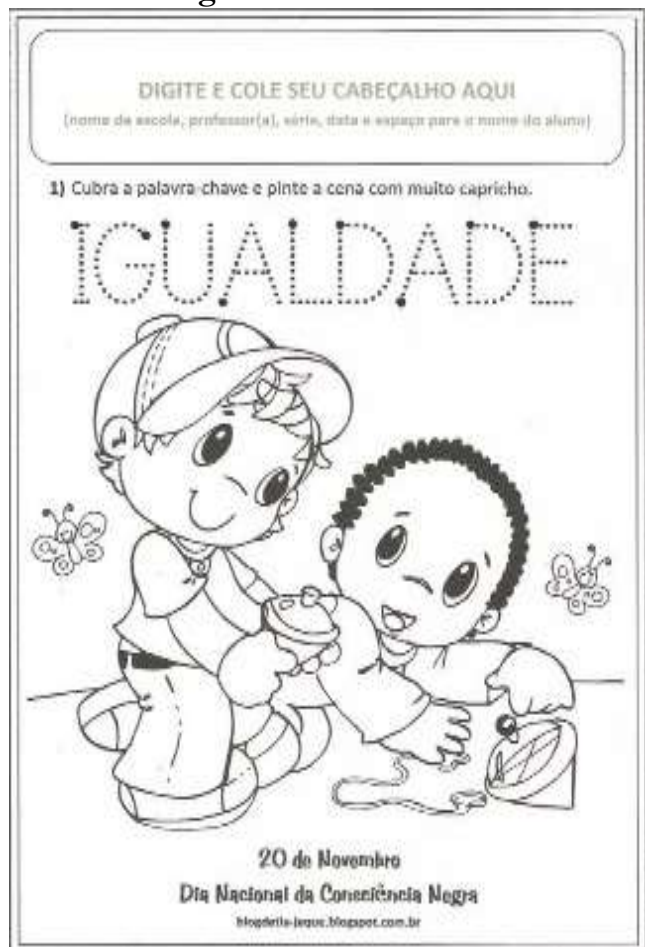

Fonte: Imagem extraída de Pinterest. ${ }^{8}$

Nessa atividade, o Locutor fala de dois lugares sociais: como locutor-docente, o qual solicita que o/a aluno/a cubra a palavra-chave e depois pinte a imagem, e como locutor-historiador, ao tratar da temática relacionada ao Dia Nacional da Consciência Negra. Embora tenha sido planejada para exercitar a pintura, a atividade traz como destaque a palavra IGUALDADE. Isso pode ser identificado no modo como ela aparece centralizada, também pela orientação do locutor-docente, que diz para o/a aluno/a como realizar a tarefa. Assim, o trabalho com a palavra aparece em primeiro plano; desse modo, primeiro há uma solicitação para cobrir a palavra-chave, e esta nomeação já produz sentidos de que ela é a parte principal da atividade, depois há uma solicitação para pintar a cena que se apresenta após a palavra.

O dizer do locutor-historiador, nessa cena enunciativa, se associa ao dizer de um enunciador-universal, para significar o Dia Nacional da Consciência Negra como o dia da IGUALDADE, esta significada na atividade como o ato de uma criança negra e uma criança branca brincarem juntas, relação de sentidos que constrói conflitos, uma vez que igualdade está constituída por outras significações, quando atreladas às questões raciais. Outro conflito que se apresenta na atividade está na relação entre a palavra igualdade e o Dia Nacional da Consciência Negra, porque os sentidos que aí são postos apagam as desigualdades, legitimam o discurso de que negros e brancos são tratados como iguais no Brasil, com os mesmos direitos e oportunidades; ao mesmo tempo, invisibilizam os movimentos políticos que estão atrelados ao 20 de novembro, a começar pela atuação política do líder Zumbi, cuja morte, ocorrida nessa data, é significada como símbolo de resistência. Em outras palavras, o Dia Nacional da Consciência Negra não foi criado para comemorar a igualdade racial no Brasil, mas para combater a ausência dessa igualdade, as injustiças sofridas pelo povo negro. Esse dia foi criado para ressaltar a continuidade da luta de negras e negros

8 Disponível em: https://br.pinterest.com/kcilenefernande/educa\%C3\%A7\%C3\%A3o-em-direitos-humanos/. Acesso em: 8 dez. 2021.

Práxis Educativa, Ponta Grossa, v. 17, e2219492, p. 1-19, 2022 Disponível em: < https:// revistas2.uepg.br/index.php/praxiseducativa> 
brasileiros/as pelo respeito e pela valorização, pelo pertencimento, pelo lugar de fala, pelos direitos que lhe são constantemente negados.

\section{Considerações finais}

As atividades que aqui analisamos apresentam sentidos divididos, muitos deles distantes dos princípios suleadores da Lei $\mathrm{N}^{\circ} 10.639 / 2003$. A primeira atividade legitima a discriminação dos povos negros, fortalece a sua exclusão do processo de construção histórica, política, social, econômica, cultural da sociedade brasileira, uma vez que, em vez de ressaltar as grandes contribuições desses povos em todas as áreas de desenvolvimento do nosso país, traz uma apresentação limitada e folclorizada dessas contribuições, como se negras e negros só tivessem capacidade para desenvolver atividades que se aprende fora do campo acadêmico, da ciência, a exemplo da dança, da música popular, da culinária que se aprende na cozinha da própria casa, cujas receitas são passadas de geração em geração. A segunda atividade, embora apresente enunciações marcadas por sentidos atrelados à resistência, à autodefinição, à autoestima, à luta, é afetada por um dizer que inferioriza o povo negro, ao apresentá-lo como uma matriz de uma sociedade falsa e desorientada. A terceira atividade é atravessada por uma concepção racista de uma igualdade sustentada pela ideologia da democracia racial, a qual amplia as desigualdades ao invés de combatêlas, criando obstáculos para que negras/os tenham acesso ao lugar de fala, aos espaços de debates, ao direito de serem ouvidos.

Diante disso, a escola precisa provocar mudanças em suas metas educacionais, no que diz respeito ao cumprimento da Lei $\mathrm{N}^{\circ} 10.639 / 2003$, a fim de garantir que negras/os brasileiros/as assumam seus lugares em espaços que até então lhes têm sido negados. Assim, poderá contribuir para superar os preconceitos e desenvolver uma consciência da História construída entre África e Brasil, trabalhando para a construção de uma identidade negra, combatendo a naturalização das práticas de racismo, discriminação e reprodução de estereótipos negativos que se direcionam aos povos negros.

\section{Referências}

ABRAMOWICZ, A.; OLIVEIRA, F. de; RODRIGUES, T. C. A criança negra, uma criança negra. In: ABRAMOWICZ, A; GOMES, N. L. (org.). Educação e raça: perspectivas políticas, pedagógicas e estéticas. Belo Horizonte: Autêntica, 2010. p. 75-96.

BANDEIRA, M. de L. Valores civilizatórios indígenas e afro-brasileiros: saberes necessários para a formulação de políticas educacionais. In: RAMOS, M. N.; ADÃO, J. M.; NASCIMENTO, G. M. (coord.). Diversidade na educação: reflexões e experiências. Brasília: Secretaria de Educação Média e Tecnológica, 2003. p. 27-34.

BRASIL. Lei N 9.394, de 20 de dezembro de 1996. Estabelece as diretrizes e bases da educação nacional. Brasília: Presidência da República, Casa Civil, Subchefia para Assuntos Jurídicos, [1996]. Disponível em: http://www.planalto.gov.br/ccivil_03/leis/19394.htm. Acesso em: 8 dez. 2021.

BRASIL. Lei No 10.639, de 9 de janeiro de 2003.Altera a Lei nำ 9.394, de 20 de dezembro de 1996, que estabelece as diretrizes e bases da educação nacional, para incluir no currículo oficial da Rede de Ensino a obrigatoriedade da temática "História e Cultura Afro-Brasileira", e dá outras providências. Diário Oficial da União: seção 1, Brasília, DF, n. 8, p. 1, 10 jan. 2003a.

BRASIL. Mensagem N No $^{\text {7, de }} 9$ de janeiro de 2003.Brasília: Presidência da República, Casa Civil, Subchefia para Assuntos Jurídicos, [2003b]. Disponível em: 
http://www.planalto.gov.br/ccivil_03/leis/Mensagem_Veto/2003/Mv07-03.htm. Acesso em: 8 dez. 2021.

BRASIL. Parecer CNE/CP N 3, de 10 de março de 2004. Diretrizes Curriculares Nacionais para a Educação das Relações Étnico-Raciais e para o Ensino de História e Cultura Afro-Brasileira e Africana. Brasília: Ministério da Educação, Conselho Nacional da Educação, [2004]. Disponível em: http://portal.mec.gov.br/dmdocuments/cnecp_003.pdf. Acesso em: 8 dez. 2021.

BRASIL. Contribuições para a Implantação da Lei 10.639/2003. Brasília: MEC, 2008. Disponível em: http://etnicoracial.mec.gov.br/publicacoes/item/4-contribuicoes-paraimplementacao-da-lei-10-639. Acesso em: 12 dez. 2021

CAMPOS, L. L. Políticas públicas de ações afirmativas: um estudo da implementação da Lei 10.639/2003 e as suas implicações nas Redes Municipais de Ensino de Porto Seguro-BA, Vitória da Conquista-BA e São Carlos-SP. 2018. Dissertação (Mestrado em Educação) - Universidade Estadual de Campinas, 2018.

GOMES, N. L. Educação e diversidade étnicocultural. In: RAMOS, M. N.; ADÃO, J. M.; NASCIMENTO, G. M. (coord.). Diversidade na educação: reflexões e experiências. Brasília: Secretaria de Educação Média e Tecnológica, 2003. p. 67-76

GOMES, N. L. Diversidade étnico-racial e educação no contexto brasileiro: algumas reflexões. In: GOMES, N L. (org.). Um olhar além das fronteiras: educação e relações raciais. Belo Horizonte: Autêntica, 2007. p. 97-109.

GOMES, Nilma Lino. Sem perder a raiz: corpo e cabelo como símbolos da identidade negra. Belo Horizonte: Autêntica, 2019.

GONZALEZ, L. Racismo e sexismo na cultura brasileira. Revista Ciências Sociais Hoje, [s. l.], v. 2, n. 1, p. 223-244, 1984.

GUIMARÃES, E. História e sentido na linguagem. Campinas: Pontes, 1989.

GUIMARÃES, E. Semântica do acontecimento: um estudo enunciativo da designação. 2.ed. Campinas: Pontes, 2005.

GUIMARÃES, E. Posfácio. Acontecimento e argumentação. In: GUIMARÃES, E. (org.). Texto e Argumentação. Campinas: Pontes, 2007a. p. 203-216.

GUIMARÃES, E. Domínio semântico de determinação. In: GUIMARÃES, E.; MOLLICA, M. C. (org.). A palavra: forma e sentido. Campinas: Pontes, RG Editores, 2007b. p. 77-96.

GUIMARÃES, E. A enumeração funcionamento enunciativo e sentido. Cadernos de Estudos Linguísticos, Campinas, v. 51, n. 1, p. 49-68, jan./jun. 2009. DOI: https://doi.org/10.20396/cel.v51i1.8637219

GUIMARÃES, E. Análise de texto: procedimento, análise, ensino. 2. ed. São Paulo: Hucitec, 2012.

GUIMARÃES, E. Ler um texto uma perspectiva enunciativa. Revista da ABRALIN, São Cristóvão, v. 12, n. 2, p. 189-205, jul./dez. 2013.

GUIMARÃES, E. Semântica, enunciação e sentido. Campinas: Pontes Editores, 2018. 
NASCIMENTO, Abdias do. O quilombismo: documentos de uma militância pan-africana. 3. ed. São Paulo: Perspectiva; Rio de Janeiro: IPEAFRO, 2019.

NASCIMENTO, V. Experiência inovadora o CEAFRO: pressupostos e metodologias. In: RAMOS, M. N.; ADÃO, J. M.; NASCIMENTO, G. M. (coord.). Diversidade na educação: reflexões e experiências. Brasília: Secretaria de Educação Média e Tecnológica, 2003. p. 155-160.

ORLANDI, E. P. Linguagem e educação social: a relação sujeito, indivíduo e pessoa. RUA, Campinas, v. 21, n. 2, p. 187-198, nov. 2015.DOI: https://doi.org/10.20396/rua.v21i2.8642454

PÊCHEUX, M. Delimitações, inversões, deslocamentos. Tradução de José Horta Nunes. Caderno de Estudos Linguísticos, Campinas, n. 19, p. 7-24, [1982] 1990. DOI: https://doi.org/10.20396/cel.v19i0.8636823

ROSS, R. Hoje na História, 20 de novembro - Dia Nacional da Consciência Negra. Portal Geledés, 20 nov. 2012. Disponível em: https://www.geledes.org.br/hoje-na-historia-20-denovembro-dia-nacional-da-consciencia-negra/. Acesso em: 8 dez. 2021.

SILVA, P. B. e. Aprender, ensinar e relações étnico-raciais no Brasil. Educação, Porto Alegre, v. 30, n. 63, p. 489-506, set./dez. 2007. 